\section{Restless legs syndrome, anxiety, and depression in phlebology practice}

\author{
Konstantin Mazayshvili, ${ }^{1,2}$ \\ Kseniya Kiyan, ${ }^{2}$ Alexey Sukhanov, ${ }^{2}$ \\ Yury Gustelev ${ }^{1}$ \\ ${ }^{1}$ Surgut State University; ${ }^{2}$ LLC Vein \\ Centre "Antireflux", Surgut, Russia
}

\begin{abstract}
The aim was to analyze the prevalence and overlapping of chronic venous disorders, restless legs syndrome, anxiety and depressive conditions. There were $582 \mathrm{sub}$ jects enroll; 450 (77.5\%) women and 132 $(22.5 \%)$ men (mean age 45.0$)$. The examination included a physical exam with ultrasound scanning, restless legs syndrome questionnaire, and the hospital anxiety and depression scale (HADS). The prevalence of chronic venous disorders was in $82.6 \%$ subjects, restless legs syndrome - $13.9 \%$, anxiety - 28\% and depression - $8.6 \%$. Chronic venous disorders were more frequent in anxious patients $(34 \% ; \mathrm{P}<0.05) v s$ non-anxious $(25 \% ; \mathrm{P}<0.05)$. Significant interrelations between chronic venous disorders and depression were not found $(\mathrm{P}>0.05)$. Anxiety and depression were significantly more frequent in patients with restless leg syndrome (anxiety 54.3\% vs non-anxiety $23.8 \%, \mathrm{P}<0.001$; depression $24.7 \%$ vs non-depression $6 \%, \mathrm{P}<0.001$ ). There were not relevant interrelations between chronic venous disorders and restless leg syndrome or anxiety/depression. Anxiety and depressive were significantly correlated with restless legs syndrome.
\end{abstract}

\section{Introduction}

Chronic venous disorders of the lower extremities (CVDs) show wide incidence which prevalence has been studied in recent decades very deeply. Despite some disagreements, most researchers consider that CVDs can affect $20 \%$ of the entire adult population. ${ }^{1-7}$ However, CVDs do not always produce symptoms, and against this background, any leg discomfort can be caused and aggravated by mental disorders (anxiety and depression, particularly) or restless leg syndrome (RLS) which occurrence is prevalent globally too. ${ }^{8}$

The first description of restless legs syndrome (RLS) was made by English anatomist and physician Thomas Willis in 1685 and verified as a specific, widespread and common condition occurring in general population by Swedish neurologist KarlAxel Ekbom in 1946. RLS is systemized in the International Statistical Classification of Diseases and Related Health Problems (ICD) under the code title G25.81 in the block Other extrapyramidal and movement disorders. According to epidemiological studies, RLS or Willis-Ekbom disease (WED) affects 3.9 to $15.0 \%$ of the adult population. ${ }^{9}$ Women suffer twice as frequently with that in men and the incidence of RLS increases in its prevalence with advancing age. ${ }^{10}$

Depression and anxiety are the most common conditions for psychiatric consultation in primary health care. ${ }^{11,12}$ These conditions can become chronic or recurrent troubling a patient's activities of daily living. Anxiety disorders are the most frequent class of mental disorders and occur in $20 \%$ of the adult population. ${ }^{11}$ Depressive disorders are seemed to be a leading cause of disability in the XXI century. They affect 3\% of the world population (216 million people) approximately. ${ }^{12}$ The prevalence of those conditions is higher in developed countries $(15 \%)$ than in developing ones $(11 \%) .{ }^{13}$ In over half of cases, depressive disorder accompanies pathological anxiety. ${ }^{14}$ And there are many patients with a combination of the two, or even three described types of disorders, which inevitably impact on the clinical picture in such patients. But, the situation of overlapping complaints on any leg discomfort with visible varicose veins induces physicians of different specialities to ping-pong these patients to vascular surgeons or phlebologists. As a rule, they do not have the professional skills of psychiatric differential exclusion and often are not informed in a possible cause of patient complaints due to mental disorders or RLS. As a result, the patient could receive the wrong treatment, which can exacerbate the symptoms. Taking into consideration the fact that symptoms of mental disorders and RLS were found in a high number of patients, it is interesting to study its prevalence and compatibility with CVDs. So the study aimed to analyze prevalence and overlapping of chronic venous disorders, restless legs syndrome, anxiety and depressive conditions in a sample of the working-age population.

\section{Materials and methods}

\section{Participants}

A total of five hundred and eighty-two (582) office employees in Moscow who voluntarily accepted to participate were included in the study. There were 450
Correspondence: Yury Gustelev, Surgut State University, 1 prospect Lenina, Surgut, 628403, Russia.

Tel.: +7.3462.55.09.03 - Fax: +7.3462.55.09.03.

E-mail: ygustelev@ya.ru

Key words: Chronic venous disorders; restless legs syndrome; anxiety; depression.

Acknowledgements: we would like to thank the Surgut State University and Vein Care Center «Antireflux» for kind cooperation and support.

Contributions: KM, study design, data collection, data analysis, writing, reviewing article; $\mathrm{KK}$, data collection, data analysis, reviewing article; AS, data collection, data analysis, reviewing article; GY, writing, reviewing article.

Conflict of interests: the authors declare no potential conflict of interest.

Received for publication: 11 November 2019

Accepted for publication: 22 January 2020.

This work is licensed under a Creative Commons Attribution 4.0 License (by-nc 4.0).

(C) Copyright: the Author(s), 2020

Licensee PAGEPress, Italy

Veins and Lymphatics 2020; 9:8672

doi:10.4081/vl.2020.8672

(77.5\%) women and $132(22.5 \%)$ men at the age of 18 to 85 years (mean age was 45.0 years). The subjects were enrolled in the study between January 2018 and November 2018. The exclusion criteria were pregnancy, anaemia, rheumatic conditions, diabetes, peripheral arterial disease, neuropathies, heart failure, and psychiatric medications intake. The research intended to analyze the prevalence and possible interrelations of CVDs with RLS, anxiety and depressive conditions in a sample of included office employees.

\section{Interventions}

All patients gave demographic data (i.e., gender, age) and detailed medical history. The examination was conducted in the workplace directly during the first half of the day and included a physical exam with simultaneous ultrasound scanning of the lower extremity veins to analyze the extent of venous disorder. The data were collected in a particular form. Pulsed colour flow Duplex ultrasonography was performed with a 4.0-13.0 MHz frequency linear probe (Ultrasound Logic V2 "General Electric", USA). The details of the normal and refluxing veins were documented, and the vein reflux was defined in the case of reverse blood flow in the vein more than $0.5 \mathrm{sec}-$ 
onds on calf muscle augmentation.

To assess the severity of CVDs signs and symptoms in the enrolled set, "C" clinical class of the clinical, etiological, anatomical and pathological (CEAP) classification was established by the researcher. "C" values were assigned to each patient in the isolated lower extremity due to the clinical category of the CEAP classification. We used the term chronic venous disorders of the lower extremities (CVDs) for all types of anatomical and functional abnormalities of the leg venous system according to the $\mathrm{C} 0-\mathrm{C} 6$ classes of CEAP classification. The term chronic diseases of the veins of the lower extremities (CVD) were applied to $\mathrm{C} 2-\mathrm{C} 6$ clinical classes only.

All patients completed an RLS symptom questionnaire, explicitly addressing the five Essential Diagnostic Criteria of RLS by 2012 Revised IRLSSG Diagnostic Criteria for RLS. ${ }^{15}$ The diagnosis of RLS had to meet all Essential Diagnostic Criteria. The Essential Diagnostic Criteria of RLS defined by the IRLSSG consensus include the five clinical diagnostic features: ${ }^{16}$ i) an urge to move the legs usually but not always accompanied by or felt to be caused by uncomfortable and unpleasant sensations in the legs; ii) the urge to move the legs and any accompanying unpleasant sensations begin or worsen during periods of rest or inactivity such as lying down or sitting; iii) the urge to move the legs and any accompanying unpleasant sensations are partially or relieved by movement, such as walking or stretching, at least as long as the activity continues; iv) the urge to move the legs and any accompanying unpleasant sensations during rest or inactivity only occur or are worse in the evening or night than during the day; v) the occurrence of the above features is not solely accounted for as symptoms primary to another medical or a behavioral condition (e.g., myalgia, venous stasis, leg edema, arthritis, leg cramps, positional discomfort, habitual foot tapping).

Unfortunately, the translation of this Essential Diagnostic Criteria to Russian is not validated yet. An assessment was performed by dichotomous choice to make the diagnosis of RLS definitive: the presence of RLS (+) or the absence of RLS (-).

Evaluation of the anxiety and depression degree was carried out by the Hospital Anxiety and Depression Scale (HADS). ${ }^{17}$ It is a frequently used self-rating scale developed to assess psychological distress in non-psychiatric patients which has been validated in Russia ${ }^{18}$ and commonly used in Russian studies. ${ }^{19}$ It composes of two subscales, Anxiety, and Depression. We felt that too much detailed gradation of anxiety and depression would not allow us to detect its effect on the CVDs symptoms statistically. Therefore, a dichotomous choice to HADS results was also used: 0 to 7 points the absence of depression/anxiety; over 8 points - the presence of anxiety/depression.

All questionnaires were used in a clinic setting before the exam. Questionnaires spent $30 \mathrm{~min}$ to fill as usual. Patients did not get any instructions in regards to how to fill but were given the standard notes and the possibility to put questions. As soon as completed, all questionnaires were checked and analyzed.

\section{Statistical analysis}

All the results are shown as percentages and mean standard deviation. Statistics fourfold tables with nonparametric statistical criteria were used to assess the statistical significance of the difference between the obtained qualitative characteristics. The minimum value of the expected phenomenon (EF) from four was determined. The Fisher's exact test was used for comparison if the minimum value of the EF was less than 5; the Pearson's chi-square test with Yates' correction for continuity was used if the minimum value of EF was in the interval from 5 to 10; Pearson's test was used if the minimum value of EF was more than 10. The odds ratio (OR) was used to quantify the significant difference. Also, the upper and lower limits of the 95\% confidence interval (CI) were calculated. Absolute and relative values of symptomatic patients are presented in the tables below.

\section{Results}

Careful data analysis has shown remarkable results. The distribution of the examined office employees by the gender and clinical class of CEAP classification is shown in Table 1.

The absence of visible or palpable signs of venous disease ( $\mathrm{C} 0$ class) was observed in men more frequently $(31.1 \%$ in men $v s$ $13.3 \%$ in women; $\mathrm{P}<0.001)$. Telangiectasia and reticular veins ( $\mathrm{C} 1$ class) are more common in women statistically $(64.0 \%$ in women vs $37.1 \%$ in men; $\mathrm{P}<0.001)$. There were not any significant gender differences in the frequency of CVD $(\mathrm{C} 2, \mathrm{C} 3, \mathrm{C} 4 \mathrm{a}+4 \mathrm{~b}$, C5, C6 clinical classes; $\mathrm{P}>0.05$ ).

The presence of RLS symptoms, according to the questionnaire, was established in 81 patients $(13.9 \%)$. The combination of these symptoms with CVDs signs (clinical classes by CEAP classification) at the same individual is presented in Table 2.

Interestingly, an increase of the CVDs clinical class according to the CEAP classification followed with a decrease in the proportion of RLS symptoms ( $\mathrm{P}>0.05)$. Against this background, we additionally performed a statistical evaluation of interrelations between the presence of CVDs symptoms and RLS according to the questionnaire. As shown in Table 3, there was no

Table 1. Patient's disposition according to chronic venous disorders' clinical class.

\begin{tabular}{|c|c|c|c|c|c|c|c|}
\hline \multirow[t]{2}{*}{ Clinical class (C) } & \multicolumn{2}{|c|}{ Men } & \multicolumn{2}{|c|}{ Women } & \multicolumn{2}{|c|}{ Total } & \multirow{2}{*}{$\begin{array}{c}\mathbf{R} \\
(\text { OR } 95 \% \mathrm{CI})^{*}\end{array}$} \\
\hline & n & $\%$ & n & $\%$ & n & $\%$ & \\
\hline $\begin{array}{l}0 \text { (no visible or palpable } \\
\text { signs of venous disease) }\end{array}$ & 41 & 31.1 & 60 & 13.3 & 101 & 17.4 & $\mathrm{P}<0.001(2.929 ; 1.852-4.630)$ \\
\hline $\begin{array}{l}1 \text { (telangiectasies, } \\
\text { reticular veins) }\end{array}$ & 49 & 37.1 & 288 & 64.0 & 337 & 57.9 & $\mathrm{P}<0.001(0.332 ; 0.222-0.496)$ \\
\hline 2 (varicose veins) & 21 & 15.9 & 65 & 14.4 & 86 & 14.8 & $P>0.05$ \\
\hline 3 (edema) & 12 & 9.1 & 32 & 7. & 44 & 7.6 & \\
\hline $4 a+4 b$ (skin changes) & 2 & 1.5 & 1 & 0.2 & 3 & 0.5 & \\
\hline 5 (healed venous ulcer) & 1 & 0.8 & 1 & 0.2 & 2 & 0.3 & \\
\hline 6 (active venous ulcer) & 6 & 4.5 & 3 & 0.7 & 9 & 1.5 & \\
\hline Total & 132 & 100 & 450 & 100 & 582 & 100 & \\
\hline
\end{tabular}

*Between male and female. 
significant difference between CVDs symptoms in groups with and without RLS $(\mathrm{P}>0.05)$. Hereafter, we analyzed significant interrelations between signs of the CVDs and status of anxiety and depression by the HADS scale (Table 4).

As shown in the table, interrelations were not found $(\mathrm{P}>0.05)$. With this context, as in the case of RLS, we also performed a statistical analysis of interrelations between CVDs symptoms and anxiety/depression according to the HADS scale (Table 5).

Symptoms of CVDs (according to CEAP classification) were significantly more frequent in anxious patients $(34 \%$;
$\mathrm{P}<0.05)$ vs non-anxious patients $(25 \%$; $\mathrm{P}<0.05)$. Significant interrelations between CVDs symptoms and depression were not found $(\mathrm{P}>0.05)$.

Finally, we performed a statistical analysis of interrelations between RLS symptoms (according to the questionnaire) and anxiety/depression status (Table 6).

Anxiety and depression were significantly more frequent in patients with RLS symptoms (according to the questionnaire) than in patients without RLS symptoms (54.3\% in anxiety patients with RLS symptoms vs $23.8 \%$ in anxiety patients without RLS symptoms, $\mathrm{P}<0.001 ; 24.7 \%$ in depres- sive patients with RLS vs $6 \%$ in depressive patients without RLS, $\mathrm{P}<0.001$ ).

A clinical evaluation summary of all possible logical relations in the study is shown in the Venn diagram (Figure 1).

Thus, there is a mosaic pattern of venous, neurological and mental disorders among the office employees. All of those disorders were found in $39(6.7 \%)$ of the examined subjects simultaneously. The absence of the above-mentioned clinical features was in one-third of the tested subjects $(n=184)$. A high frequency $(30 \%)$ of anxiety and depressive disorders were observed.

Table 2. Chronic venous disorders' clinical class in patients with restless legs syndrome.

\begin{tabular}{|c|c|c|c|c|c|c|}
\hline \multirow[t]{2}{*}{ Clinical class $(\mathrm{C})$} & \multirow[t]{2}{*}{ n } & \multicolumn{2}{|c|}{ RLS + } & \multicolumn{2}{|c|}{ RLS- } & \multirow{2}{*}{$\begin{array}{c}\mathbf{R} \\
(\text { OR } 95 \% \mathrm{CI}) *\end{array}$} \\
\hline & & n & $\%$ & n & $\%$ & \\
\hline $\mathrm{C} 0-\mathrm{Cl}$ & 438 & 66 & 81.5 & 372 & 74.3 & $P>0.05$ \\
\hline C2-C3 & 150 & 12 & 14.8 & 118 & 23.6 & \\
\hline C4-C6 & 14 & 3 & 3.7 & 11 & 2.2 & \\
\hline Total & 582 & 81 & 100.0 & 501 & 100.0 & \\
\hline
\end{tabular}

*Between patients with RLS (RLS+) and without it (RLS-).

Table 3. Chronic venous disorders symptoms in patients with restless legs syndrome.

\begin{tabular}{|c|c|c|c|c|c|c|}
\hline \multirow[t]{2}{*}{ CVDs symptoms } & \multirow[t]{2}{*}{ n } & \multicolumn{2}{|c|}{ RLS + } & \multicolumn{2}{|c|}{ RLS- } & \multirow{2}{*}{$\begin{array}{c}\mathbf{R} \\
(\text { OR } 95 \% \mathrm{CI}) *\end{array}$} \\
\hline & & n & $\%$ & n & $\%$ & \\
\hline A - without symptoms (CEAP) & 388 & 53 & 65.4 & 335 & 66.9 & $P>0.05$ \\
\hline S - with symptoms (CEAP) & 194 & 28 & 34.6 & 166 & 33.1 & $P>0.05$ \\
\hline Total & 582 & 81 & 100 & 501 & 100 & \\
\hline
\end{tabular}

*Between patients with RLS (RLS+) and without it (RLS-).

Table 4. Chronic venous disorders clinical class in anxiety and depression groups.

\begin{tabular}{|c|c|c|c|c|c|c|c|c|c|c|c|c|}
\hline \multirow[t]{2}{*}{ Clinical class $(\mathrm{C})$} & \multirow[t]{2}{*}{ n } & \multicolumn{2}{|c|}{$\begin{array}{l}\text { Group A } \\
\text { No anxiety } \\
(n=419)\end{array}$} & \multicolumn{2}{|c|}{$\begin{array}{l}\text { Group B } \\
\text { anxiety } \\
(\mathrm{n}=163)\end{array}$} & \multirow[t]{2}{*}{$\begin{array}{c}\text { p } \\
(\text { OR } 95 \% \\
\text { CI)** }\end{array}$} & \multirow[t]{2}{*}{ n } & \multicolumn{2}{|c|}{$\begin{array}{l}\text { Group C } \\
\text { No Depression } \\
(\mathrm{n}=532)\end{array}$} & \multicolumn{2}{|c|}{$\begin{array}{l}\text { Group D } \\
\text { Depression } \\
(\mathrm{n}=\mathbf{5 0})\end{array}$} & \multirow[t]{2}{*}{$\begin{array}{c}\mathbf{R} \\
(\text { OR } 95 \% \\
\text { CI) })^{* *}\end{array}$} \\
\hline & & n & $\%$ & n & $\%$ & & & n & $\%$ & n & $\%$ & \\
\hline $\mathrm{C} 0-\mathrm{Cl}$ & 438 & 314 & 74.9 & 124 & 76.1 & $p>0.05$ & 438 & 403 & 75.8 & 35 & 70.0 & $\mathrm{P}>0.05$ \\
\hline $\mathrm{C} 2-\mathrm{C} 3$ & 133 & 98 & 23.4 & 35 & 21.5 & $p>0.05$ & 133 & 118 & 22.2 & 15 & 30.0 & $P>0.05$ \\
\hline C4-C6 & 11 & 7 & 1.7 & 4 & 2.5 & $p>0.05$ & 11 & 11 & 2.1 & 0 & 0.0 & $P>0.05$ \\
\hline Total & 582 & 419 & 100.0 & 163 & 100.0 & & 582 & 532 & 100.0 & 50 & 100.0 & \\
\hline
\end{tabular}

*Between A and B groups; **between C and D groups.

Table 5. Chronic venous disorders symptoms in anxiety and depression groups.

\begin{tabular}{|c|c|c|c|c|c|c|}
\hline \multirow{2}{*}{$\begin{array}{l}\text { Presence of anxiety } \\
\text { and depression }\end{array}$} & \multirow[t]{2}{*}{ n } & \multicolumn{2}{|c|}{ A - CVDs symptoms - S - } & \multicolumn{2}{|c|}{ CVDs symptoms + } & \multirow[t]{2}{*}{ R (OR 95\% CI) * } \\
\hline & & n & $\%$ & n & $\%$ & \\
\hline No anxiety & 419 & 291 & 75.0 & 128 & 66.0 & $\mathrm{P}<0.05(1.547 ; 1.063-2.252)$ \\
\hline Anxiety & 163 & 97 & 25.0 & 66 & 34.0 & \\
\hline Total & 582 & 388 & 100 & 194 & 100 & \\
\hline No depression & 532 & 350 & 90.2 & 182 & 93.8 & $P>0.05$ \\
\hline Depression & 50 & 38 & 9.8 & 12 & 6.3 & \\
\hline Total & 582 & 388 & 100 & 194 & 100 & \\
\hline
\end{tabular}

*Between patients with (+) and without (-) CVDs symptoms (according to CEAP classification). 


\section{Discussion}

In recent work, E.I. Seliverstov et al. ${ }^{20}$ provide good critical analysis of the previous epidemiological studies of CVDs. Studies with nonrandom samples take in fair criticism. Accordingly, the results of such studies cannot be extrapolated to the general population. We are aware of the biased sample of our research.

Nevertheless, E.I. Seliverstov et al. ${ }^{20}$ point out that ...knowledge of the prevalence of CVD in the Russian population is important not only from an academic point of view but also is significant for planning and solving the healthcare organization tasks. It is essential to recall that for resolving these tasks, and it is crucial to segment possible recipients of appropriate medical care and develop special programs for each group of patients. Our study was conducted for the segment of the working population in Moscow, and its results can be extrapolated to the entire part. We also realize that we used an unvalidated RLS questionnaire in Russia. ${ }^{21}$ Nevertheless, taking into account the lack of validated RLS questionnaires in Russian, we took this step, knowing that our study results could be reasonably criticized.

Our study demonstrates the high prevalence of CVDs that has reached $82.6 \%$. This value comes close to $83.6 \%$ in the Vein Consult study that also explored the prevalence of CVDs in 20 countries. ${ }^{7}$ The absence of vein disorders symptoms by clinical examination was revealed in 101 people $(17.3 \%)$, which is very similar to the data of the most extensive phlebological study conducted in 53 Italian cities and involving more than 15,000 people $(20.9 \%){ }^{23}$ C2 clinical class was found in $14.8 \%$ of patients. However, it was slightly lower than in the Russian population study $(19.3 \%) .{ }^{22}$ In general, C3-C6 clinical classes, i.e. advance and complicated forms of
CVD were met in $9.9 \%$ of cases. It slightly differs from the same study $(7.4 \%) .^{22}$ However, this is more than half lower than $23.2 \%$ obtained in Italy. ${ }^{23}$ Indeed, such a difference requires further investigations.

According to the World Health Organization (WHO), about $50 \%$ of the world's population faced up with mental disorders intra vitam. Depression and anxiety disorders take leading positions among them. ${ }^{24}$ In our work, an increased level of anxiety was detected in $163(28 \%)$ of the examined subjects. Signs of depression were rarely detected - in $50(8.6 \%)$ subjects.
By comparison with the results obtained in the well-planned 12-month observational study conducted in the United States, our data was close to the American one: anxiety was diagnosed in $18.1 \%$ of cases, while depression was diagnosed in $9.5 \%$ cases. ${ }^{25}$ Meanwhile, such a difference between data should not be a surprise: anxious and depressive disorders can appear and disappear for many reasons - from a social and cultural environment to fiscal health. ${ }^{13}$

Population studies show that the prevalence of RLS is $5-15 \% .{ }^{9}$ However, there is an opinion that these data are overstated

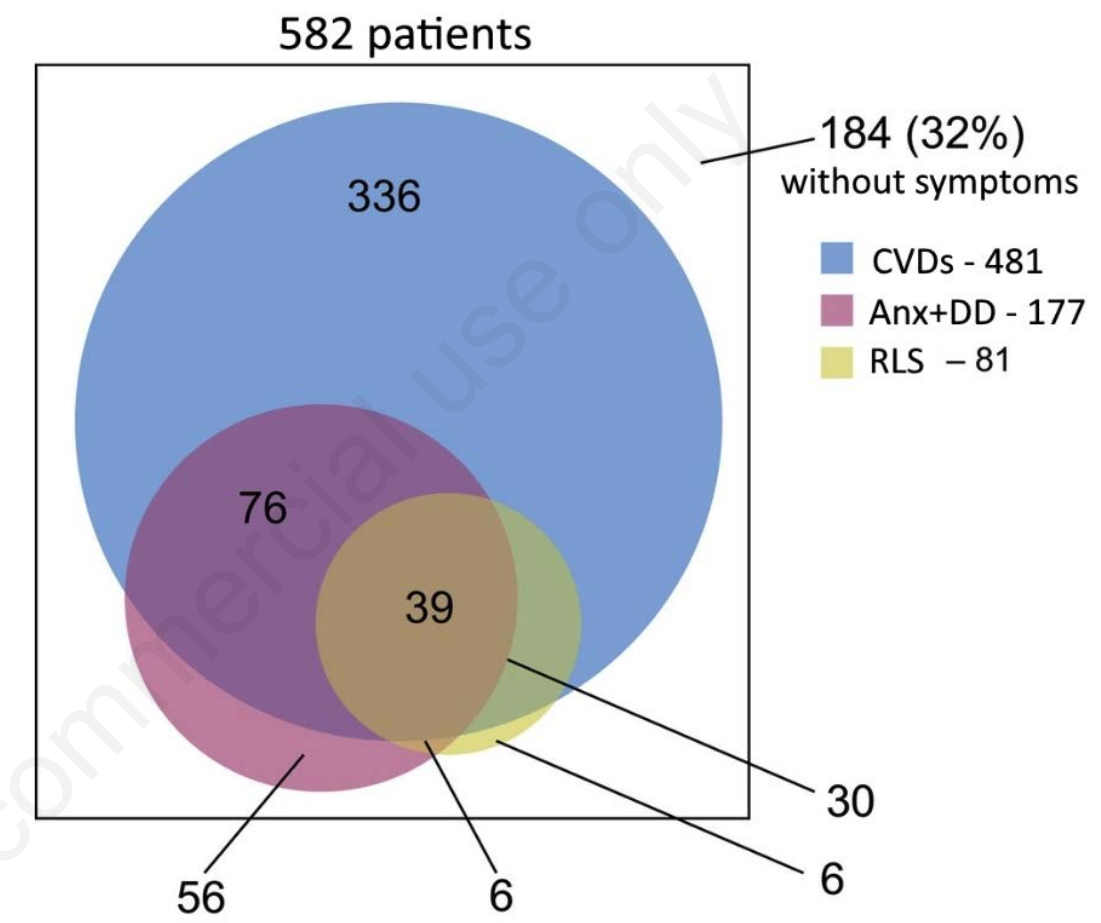

Figure 1. Chronic venous disorders symptoms (CVDs), restless legs syndrome (RLS), anxiety (Anx) and depression disorders (DD) interrelations.

Table 6. Anxiety/depression status in patients with restless legs syndrome.

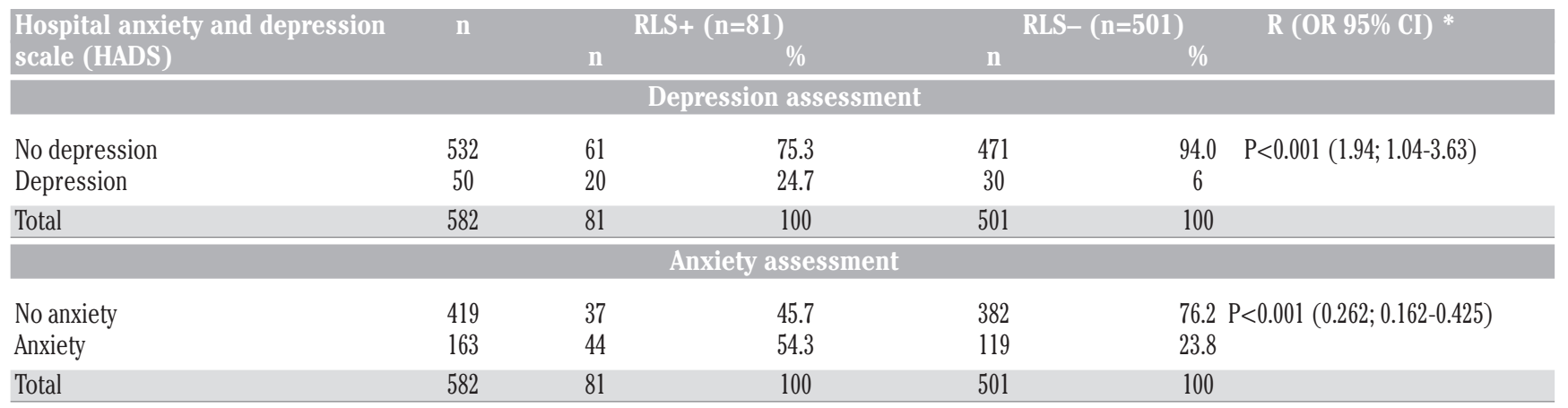

*Between patients with RLS (RLS+) and without it (RLS-). 
because most epidemiological studies were conducted using questionnaires. ${ }^{26}$ In our work, RLS occurred in $14 \%$ of the subjects. We understand that the questionnaire appliance (especially unvalidated in Russia) could also affect the results and slightly confound it.

The occurrence of depression and anxiety disorders in patients with CVDs has not understood well due to the small number of studies. It should also be noted a significantly higher rate of anxiety and depressive disorders among comorbid mental disorders in patients with RLS. Fink P et al. (2004) recorded manifestations of depression in $11 \%$ of patients with RLS. ${ }^{26}$ According to Hochang et al., ${ }^{27} 19.5 \%$ of patients with RLS had a depressive state, and $16.7 \%$ had panic disorders. Hornyak ${ }^{28}$ believe that RLS can cause secondary depressive symptoms due to prolonged sleep disorders. In our study, depression was statistically more frequent in patients with RLS. Anxiety disorders are also significantly associated with RLS (54.3\% with RLS vs 23.8\% without RLS). These data fully correspond to the results $(21.1 \%$ of depressive and anxiety disorders with RLS and $4.5 \%$ - without RLS) in a large study (3481 subjects) performed in the USA (in Baltimore). ${ }^{29}$

Curiously, Kanter et al. found the interrelation of reflux and RLS manifested in the improvement of RLS symptoms after sclerotherapy. ${ }^{30}$ Further investigators outlined these interrelations in RLS patients with primary and recurrent varicose veins..$^{31,32}$ Eliminating of superficial venous reflux has been demonstrated to reduce RLS symptoms. ${ }^{33}$

The interrelations between CVDs, anxiety/depression, and RLS during our study showed that 39 of the enrolled subjects had all three of the disorders. High frequency of anxiety and depressive disorders was noted, and their combinations with CVDs in 39 people ( $6.7 \%$ of all subjects) was observed. This fact is alarming that patients' complaints sometimes have a psychogenic (rather than venous or any other) nature. It must be emphasized that among the patients with the lack of CVDs symptoms or with telangiectasies and reticular veins only, a significant part of complaints has a nonvenous origin. Also, $32 \%$ of the surveyed subjects did not have any venous, mental or neurologic signs and symptoms.

\section{Conclusions}

Thus, the prevalence of CVDs in our study corresponds to other epidemiologic data and comprises $82.6 \%$ for C1-C6 clini- cal classes. Anxiety was found in 163 subjects $(28 \%)$, and depression was detected in 50 subjects $(8.6 \%)$. RLS was identified in $81(14 \%)$ of the surveyed subjects according to the questionnaire. About one in four of the studied subjects with CVDs symptoms showed a combination of RLS and mental disorders. It was not realistic to reveal the interrelations between CEAP clinical class and RLS as the same as with the presence and level of mental disorders. Also, there was no correlation between the CVDs symptoms in patients with and without RLS. Significant interrelations between RLS and depressive disorders were revealed: depression in patients with RLS occurred four times more often than in the cases of RLS absence. Approximately onethird of the subjects did not have any venous, mental or neurologic signs and symptoms.

Nevertheless, we consider that evaluation of RLS, anxiety and depression symptoms in CVDs patients can be utilized and optionally helpful to recognize management strategies of these comorbid conditions. By the way, CVDs, RLS, anxiety, and depression can be managed well, and a multi-disciplinary approach to those patients is suggested from the above reasoning.

\section{References}

1. Zolotukhin IA, Seliverstov EI, Shevtsov YN, et al. Prevalence and risk factors of Chronic Venous Disease in the General Russian Population. Eur J Vasc Endovasc Surg 2017;54:752-8.

2. Mazajshvili KV, Chen VI. Chronic venous diseases of lower limbs in Petropavlovsk-Kam chatksky. Flebologiya 2008;2:52-4 [In Russian].

3. Kirienko AI, Bogachev VY, Gavrilov $\mathrm{SG}$, et al. Chronic venous diseases of lower extremities in industrial workers of Moscow (Results of the epidemiological survey). Angiol Sosudist Hirur 2004;10:77 [In Russian].

4. Beebe-Dimmer JL, Pfeifer JR, Engle JS, Schottenfeld D. The epidemiology of chronic venous insufficiency and varicose veins. Ann Epidemiol 2005;15:175-84.

5. Chiesa R, Marone E, Limoni C, et al. Chronic Venous Insufficiency in Italy: The 24-cities Cohort Study. Eur J Vasc Endovasc Surg 2005;30:422-9.

6. Criqui MH, Jamosmos M, Fronek A, et al. Chronic Venous Disease in an Ethnically Diverse Population: The San Diego Population Study. Am J Epidemiol 2003;158:448-56.
7. Rabe E, Guex JJ, Puskas A, et al. Epidemiology of chronic venous disorders in geographically diverse populations: results from the Vein Consult Program. Int Angiol 2012;31:105-15.

8. Antropov Yu, Antropov AY, Neznanov NG. Essential diagnostic of mental disorders. Moskow: GEOTAR-Media; 2010 [In Russian].

9. Ohayon MM, O’Hara R, Vitiello MV. Epidemiology of restless legs syndrome: A synthesis of the literature. Sleep Med Rev 2012;16:283-95.

10. Allen RP, Walters AS, Montplaisir J, et al. Restless Legs Syndrome Prevalence and Impact: REST general population study. Archiv Intern Med 2005;165: 1286-92.

11. Kessler RC, Chiu WT, Demler O, Walters EE. Prevalence, Severity, and Comorbidity of 12-Month DSM-IV Disorders in the National Comorbidity Survey Replication. Archiv General Psychiatry 2005;62:617.

12. Vos T, Allen C, Arora M, et al. Global, regional, and national incidence, prevalence, and years lived with disability for 310 diseases and injuries, 1990-2015: a systematic analysis for the Global Burden of Disease Study 2015. Lancet 2016;388:1545-602.

13. Kessler RC, Bromet EJ. The Epidemiology of Depression Across Cultures. Ann Rev Public Health 2013;34:119-38.

14. Kaufman J, Charney D. Comorbidity of mood and anxiety disorders. Depress Anxiety 2000;12 Suppl 1:69-76.

15. Mazayshvili RV, Kian KA, Khlevtova $\mathrm{TV}$, et al. The patient with COS and C1S: Should a Phlebopathy Be Concidered? Flebologiya 2016;10:137 [In Russian].

16. Allen RP, Picchietti DL, GarciaBorreguero D, et al; International Restless Legs Syndrome Study Group. Restless legs syndrome/Willis-Ekbom disease diagnostic criteria: updated International Restless Legs Syndrome Study Group (IRLSSG) consensus criteria - history, rationale, description, and significance. Sleep Med 2014;15:860-73.

17. Zigmond AS, Snaith RP. The Hospital Anxiety and Depression Scale. Acta Psychiatr Scandinav 1983;67:361-70.

18. Andryushenko AV, Drobizhev MY, Dobrovolsky AV. Comparative evaluation of CES-D, BDI and HADS (d) scales for depression diagnostic in general health practice. Zhurnal Nevrol Psihiatr S.S. Korsak 2003;(5):11-8 [In Russian].

19. Shalnova SA, Evstifeeva SE, Deev AD, 
et al. The prevalence of anxiety and depression in different regions of the Russian Federation and its association with demographic factors (according to the data of the ESSE-RF study). Terapevticheskij Arhiv 2014;86:53-60 [In Russian].

20. Seliverstov EA, Avakyants IP, Nikishkov AS, Zolotuhin IA. Epidemiology of Chronic Venous Diseases. Flebologiya 2016;10:35-42 [In Russian].

21. Zolotuhin IA, Seliverstov EI, Shevtsov Yu, et al. Prevalence of Chronic Venous Disease: Results of Population-Based Epidemiological Study. Flebologiya 2016;10:119-25 [In Russian].

22. Chiesa R, Marone EM, Limoni C, et al. Chronic venous disorders: Correlation between visible signs, symptoms, and presence of functional disease. $\mathrm{J}$ Vasc Surg 2007;46:322-30.

23. Andrade L, Caraveo-Anduaga JJ, Berglund $\mathrm{P}$, et al. Cross-national comparisons of the prevalences and correlates of mental disorders; WHO International Consortium in Psychiatric
Epidemiology. Bull World Health Organ 2000;78:413-26.

24. Kessler RC, Chiu WT, Demler O, Walters EE. Prevalence, Severity, and Comorbidity of 12-Month DSM-IV Disorders in the National Comorbidity Survey Replication (NCS-R). Archiv Gener Psychiatry 2005;62:617-27.

25. Levin O.S. Restless legs syndrome. Zemskij Vrach 2010;4:11-6 [In Russian].

26. Fink P, Hansen M, Oxhoj M. The prevalence of somatoform disorders among internal medical inpatients. J Psychosom Res 2004;56:413-8.

27. Hochang B, Wayne A. Restless Legs Syndrome is Associated with DSM-IV Major Depressive Disorder and Panic Disorder in the Community. J Neuropsychiat Clin Neurosci 2008;20:101-5.

28. Hornyak M. Depressive disorders in Restless Legs Syndrome. CNS Drugs 2010;24:89-98.

29. Lee HB, Hening WA, Allen RP, et al. Restless legs syndrome is associated with DSM-IV major depressive disor- der and panic disorder in the community. J Neuropsychiatr Clin Neurosci 2008;20:101-5.

30. Kanter AH. The effect of sclerotherapy on restless legs syndrome. Dermatol Surg 1995;21:328-32.

31. McDonagh B, Huntley DE, Rosenfeld $\mathrm{R}$, et al. Efficacy of the Comprehensive Objective Mapping, Precise Image Guided Injection, Anti-Reflux Positioning and Sequential Sclerotherapy (COMPASS) technique in the management of greater saphenous varicosities with saphenofemoral incompetence. Phlebology 2002;17:1928.

32. McDonagh B, Sorenson S, Gray C, et al. Clinical spectrum of recurrent postoperative varicose veins and efficacy of sclerotherapy management using the compass technique. Phlebology 2003; 18:173-85.

33. Hayes CA, Kingsley JR, Hamby KR, Carlow J. The effect of endovenous laser ablation on restless legs syndrome. Phlebology 2008;23:112-7. 